\title{
Postural control and fear of falling in persons with low-level paraplegia
}

\author{
Ligie T. John, BPT; Binu Cherian, BPT, PGDHM; ${ }^{*}$ Andrew Babu, MPT \\ Physiotherapy Service, Department of Physical Medicine and Rehabilitation, Christian Medical College, Vellore, India
}

\begin{abstract}
Falls are prevalent reasons for spinal cord injury (SCI). Postinjury fear of falling (FOF) can affect rehabilitation potential. We quantified FOF in 15 men with paraplegia (ambulatory with bilateral knee-ankle-foot orthoses [KAFOs] and elbow crutches) in correlation with their postural control at the center for long-term SCI rehabilitation of a tertiary-care teaching hospital. Our outcome measures comprised the American Spinal Injury Association Impairment Scale, the Modified Falls Efficacy Scale (MFES), postural sway measurements in the anteroposterior and mediolateral directions; and walking speed, cadence, and endurance. We assessed FOF with the MFES followed by measuring postural sway with a force platform. We measured gait parameters by asking the participant to ambulate on an indoor pathway. The mean postural sway was $314.13+/-$ $184.05 \mathrm{~mm}$ (mean +/- standard deviation) in the anteroposterior direction and $222.16+/-112.34 \mathrm{~mm}$ in the mediolateral direction. The MFES score was $41.29+/-12.77$, which showed a statistically significant negative correlation with postural control. The self-perception of confidence as measured by MFES might not really represent the actual postural stability in individuals with low-level paraplegia. FOF can adversely affect the postural control of individuals with low-level paraplegia. Clinicians should consider FOF as an influential factor in postural control during rehabilitation.
\end{abstract}

Key words: ambulation, fear of falling, knee-ankle-foot orthoses, paraplegia, postural control, rehabilitation, spinal cord injury, walking cadence, walking endurance, walking speed.

\section{INTRODUCTION}

Rehabilitation after spinal cord injury (SCI) is primarily based on the neurological level. The amount of motor and sensory preservation decides the patient's ambulation potential [1]. Most individuals with low-level paraplegia can become ambulatory with knee-ankle-foot orthoses (KAFOs). Paraplegic ambulation using KAFOs has been well documented in the literature [2]. KAFO use allows patients access to confined areas in the home and workplace and entrance to non-wheelchair-accessible venues [3].

Static and dynamic control over the stance phase is a precursor for gait training with KAFOs. The standing posture of an individual with paraplegia using KAFOs is referred to as the " $C$ " posture. The patient is trained to hyperextend the lumbar (L) spine and hips to balance the head, arms, and trunk over the legs. The anterior femoral ligament provides stability in the sagittal plane, while trunk muscles with or without arm support contribute to coronal plane stability. Many individuals with low-level paraplegia can achieve static balance of unsupported standing with their hands raised above their head. This independent standing is important for performing bimanual activities of daily living (ADLs), such as dressing and opening a bottle [4].

Falls are one of the most prevalent reasons for SCI, which might later be reflected in fear of falling (FOF)

\footnotetext{
Abbreviations: ADL = activity of daily living, AIS = American Spinal Injury Association Impairment Scale, COP = center of pressure, FOF = fear of falling, KAFO = knee-ankle-foot orthosis, $\mathrm{L}=$ lumbar, MFES = Modified Falls Efficacy Scale, $\mathrm{SCI}=$ spinal cord injury, $\mathrm{T}=$ thoracic.

*Address all correspondence to Binu Cherian, BPT, PGDHM; Christian Medical College-Physiotherapy Service, PMR Department, Vellore, Tamilnadu 632004, India; +91-416-2282663; fax: +91-416-2232035.

Email: binucherianbpt@gmail.com

DOI:10.1682/JRRD.2009.09.0150
} 
during the rehabilitation process [5]. Such a fear may result in a self-imposed decline in activity and function. Overcoming a patient's FOF can be a great challenge to clinicians. Therefore, the estimation of degree of FOF enables the clinician to modify the rehabilitation program by incorporating different exercises and/or counseling sessions. These modifications are of value in beating FOF and achieving successful rehabilitation.

Individuals with SCI who were ambulatory had a higher incidence of subsequent injuries due to a variety of causes, including impaired balance or gait associated with falls [6]. Brotherton et al. found that falls are a significant problem among ambulatory individuals with SCI, both in terms of frequency and consequence [7-8]. They suggested incorporating specific and objective clinical tests and measures into the examination of falls to better identify the particular factors that may be associated with falls. Control of posture in the standing position is the prime factor in fall prevention. Clinically, patients with better postural control were found to have good transfer and ambulation skills. Knowledge of any possible relationships between these factors contributes to the rehabilitation process by enabling clinicians to avoid fall incidents during training sessions. Studies have assessed FOF in the elderly population [9] and in persons with Parkinson disease [10] and stroke [11]. Lin et al. investigated the kinematic, kinetic, and electromyographic aspects of postural control during falling with rapid reach-and-grasp balance reaction in individuals with thoracic (T) SCI wearing KAFOs [12]. They concluded that back postural muscles alone are not sufficient to maintain balance. No studies exist on FOF and its possible relationship with postural control of persons with complete paraplegia. Hence, we designed this study to estimate FOF in individuals with paraplegia using bilateral KAFOs and elbow crutches and its effect on their postural control. We hypothesized that individuals with paraplegia with higher FOF who are ambulatory with bilateral KAFOs and elbow crutches will have less postural control. The study also explored the relationship between postural control and gait parameters in individuals with paraplegia.

\section{METHODS}

We selected the participants for this correlative study from an SCI rehabilitation center at a tertiary-care univer- sity teaching hospital where the average inpatient rehabilitation program extends 12 weeks. We consecutively recruited 15 men with a diagnosis of T8 to L1 American Spinal Injury Association Impairment Scale (AIS) A levels during the final stages of their rehabilitation program. All participants were between 15 and 45 years old. The other inclusion criteria were the ability to ambulate independently with bilateral KAFOs for a minimum of $50 \mathrm{~m}$ using an elbow crutch-assisted reciprocal 4-point gait pattern, the ability to stand independently for at least $90 \mathrm{~s}$, and current or completed inpatient gait training. We excluded participants who were female, were an ethnic group other than Asian-Indian, had a body mass index $<18.5$ or $>24.9$, had any associated injuries (head injury; lower-limb and upper-limb fractures and pressure sores; and incomplete AIS B, C, and D levels), and had any psychiatric comorbidities. We based the selection criteria of the participants on the earlier research findings that postural sway measurements can vary according to age, sex, body mass index, and ethnicity [13]. We informed all participants about the study protocol, and they signed a consent form.

\section{Outcome Measures}

\section{American Spinal Injury Association Impairment Scale}

The AIS is the recommended instrument for assessing sensory and motor function after SCI [14]. Kappa values for interrater reliability of the AIS have been estimated to range from 0.47 to 0.87 for the motor portion and from 0.06 to 0.93 for the sensory portion [15] and are used in clinical trials of locomotor training [16]. Table 1 outlines the scale.

\section{Modified Falls Efficacy Scale}

The Modified Falls Efficacy Scale (MFES) is a 14item rating scale used to assess confidence in performing ADLs without falling [17]. Different versions of the MFES are available in the literature. The MFES we used is the U.K. version, in which each item is rated from 1 (extreme confidence) to 10 (no confidence at all) [18]. Participants who reported avoiding activities because of FOF had higher MFES scores, representing lower selfefficacy or confidence, than those not reporting FOF. The independent predictors of MFES are usual walking pace (a measure of physical ability), anxiety, and depression. Retest reliability for the MFES was high (intraclass correlation coefficient $=0.58$ ) and internal reliability was excellent (Cronbach alpha $=0.97)[18]$. Use of the Falls 
Table 1.

American Spinal Injury Association Impairment Scale.

\begin{tabular}{|c|c|c|}
\hline Level & $\begin{array}{l}\text { Functional } \\
\text { Impairment }\end{array}$ & Description \\
\hline $\mathrm{A}$ & Complete & $\begin{array}{l}\text { No motor or sensory function is pre- } \\
\text { served in S4-S5. }\end{array}$ \\
\hline B & Incomplete & $\begin{array}{l}\text { Sensory, but not motor function, is } \\
\text { preserved below neurological level } \\
\text { and includes S4-S5. }\end{array}$ \\
\hline $\mathrm{C}$ & Incomplete & $\begin{array}{l}\text { Motor function is preserved below } \\
\text { neurological level, and more than } \\
\text { half of key muscles below neurologi- } \\
\text { cal level have muscle grade }<3 \text {. }\end{array}$ \\
\hline $\mathrm{D}$ & Incomplete & $\begin{array}{l}\text { Motor function is preserved below } \\
\text { neurological level, and at least half } \\
\text { of key muscles below neurological } \\
\text { level have muscle grade of } \geq 3 \text {. }\end{array}$ \\
\hline $\mathrm{E}$ & Normal & $\begin{array}{l}\text { Motor and sensory functions are } \\
\text { normal. }\end{array}$ \\
\hline
\end{tabular}

Efficacy Scale, the earlier version of MFES, has been reported in patients with SCI [19].

\section{Postural Sway}

Measurement of postural sway is based on the registration and analysis of the vertical forces produced by the participant and communicated to the force platform surface. We registered the vertical forces using transducers attached at each corner of a Good Balance triangular force platform (Metitur Oy; Jyväskylä, Finland). For the postural sway measurement, the participant must stand in the center of the platform with his eyes fixed at a distance of $3 \mathrm{~m}$ for $30 \mathrm{~s}$. Computer software provides the postural sway measurement in two-dimensional values. The use of force platforms for balance assessment is well-documented in the rehabilitation literature [20].

\section{Gait Parameters}

- Speed in meters per second. Walking speed in the second minute of a 3 min walking session.

- Cadence in steps per minute. Number of steps in the second minute of a 3 min walking session.

- Endurance in meters. Maximum distance the participant can walk with no rest.

\section{Procedure}

We asked the participants to fill out the MFES before the postural sway measurement with the Good Balance.
We then asked participants to stand on the force platform with their gaze fixed at a spot $3 \mathrm{~m}$ in the distance. We took each measurement for $30 \mathrm{~s}$. We performed three measurements and considered the average values for the statistical analysis. We measured gait parameters by asking the participant to walk with their bilateral KAFOs and elbow crutches on a $500 \mathrm{~m}$ indoor pathway. We asked participants to walk for $3 \mathrm{~min}$ and recorded the speed and cadence during the second minute of the session by using a handheld stopwatch. We measured gait endurance in another walking session in which we asked the participants to walk to their maximum distance without taking a rest.

\section{Statistical Analysis}

We analyzed data using SPSS for Windows (SPSS Inc; Chicago, Illinois) [21]. We calculated the Pearson correlation coefficient between FOF and each parameter of the postural control measurements. We set the significance level at $p \leq 0.05$. We correlated mean postural sway of center of pressure (COP) along the $x$-axis (in the mediolateral direction), mean postural sway of COP along the $y$-axis (in the anteroposterior direction), and velocity moment (moment of velocity from the path of the center of forces) with the MFES scores and the participants' lesion levels. We analyzed the MFES scores against the gait parameters of speed, cadence, and endurance.

\section{RESULTS}

The Figure shows the distributions of participant's lesion levels. Table 2 gives participants' characteristics. The mean MFES scores were $41.29 \pm 12.77$ (mean \pm standard deviation). The mean postural sway was $314.13 \pm$ $184.05 \mathrm{~mm}$ in the anteroposterior direction (Extent $y$ ) and $222.16 \pm 112.34 \mathrm{~mm}$ in the mediolateral direction (Extent $x$ ). Table 3 summarizes the postural sway measurements, gait parameters, and MFES score.

The results showed a negative correlation between MFES and force platform parameters, of which the Extent $x$ and Mean $x$ speed were statistically significant. We found no statistically significant correlations between the gait parameters and MFES scores. Table $\mathbf{4}$ shows statistical significance between the various parameters studied. 


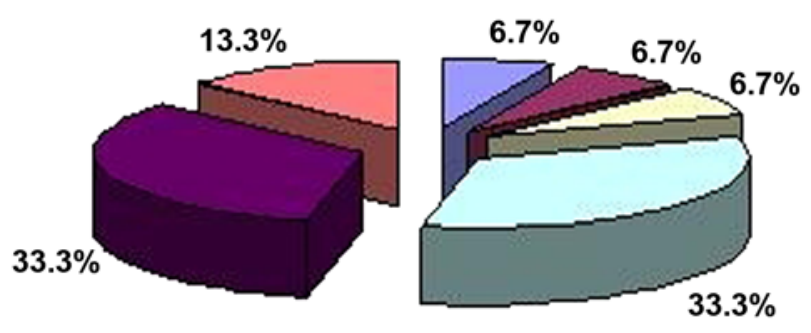

T8 $\square$ T9 $\square$ T10 $\square$ T11 $\square$ T12 $\square \mathrm{L1}$

Figure.

Lesion level distribution of participants. $\mathrm{L}=$ lumbar, $\mathrm{T}=$ thoracic.

Table 2.

Participant characteristics $(n=15)$.

\begin{tabular}{lc}
\hline \multicolumn{1}{c}{ Characteristic } & Value \\
\hline Age (yr, mean \pm SD) & $29.87 \pm 9.21$ \\
Height (cm, mean \pm SD) & $168.10 \pm 7.12$ \\
Weight (kg, mean \pm SD) & $58.00 \pm 11.44$ \\
Etiology of Spinal Cord Injury (\%) & \\
$\quad$ Traumatic & 86.7 \\
$\quad$ Ischemic & 13.3 \\
\hline SD = standard deviation.
\end{tabular}

Table 3.

Postural sway measurements, gate parameters, and Modified Falls Efficacy Scale (MFES) scores.

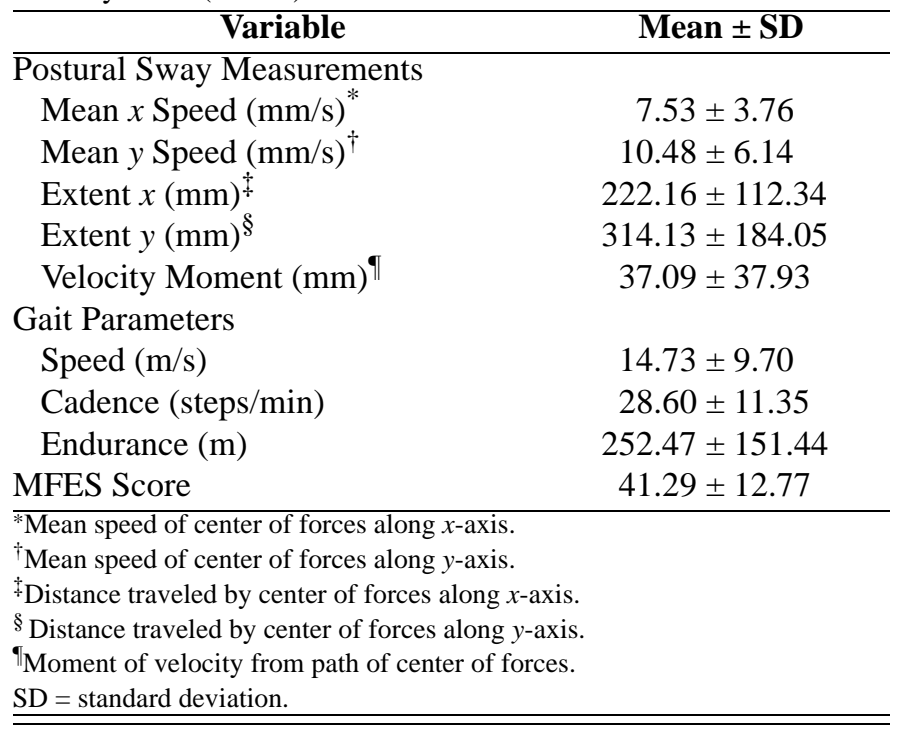

\section{DISCUSSION}

The present study is the first of its kind in the field of FOF among ambulatory individuals with paraplegia. The study quantified FOF, which is an important consider-
Table 4.

Statistical significance of study parameters.

\begin{tabular}{lcc}
\hline \multicolumn{1}{c}{ Statistical Analysis } & $\begin{array}{c}\text { Pearson } \\
\text { Correlation } \\
\text { Coefficient }\end{array}$ & $\begin{array}{c}\text { Significance } \\
\text { (2-tailed) }\end{array}$ \\
\hline MFES vs Extent $x$ & -0.54 & $0.04^{*}$ \\
MFES vs Extent $y$ & -0.52 & $0.05^{*}$ \\
MFES vs Mean $x$ Speed & -0.54 & $0.04^{*}$ \\
MFES vs Mean $y$ Speed & -0.52 & $0.05^{*}$ \\
MFES vs Velocity Moment & -0.43 & 0.11 \\
MFES vs Velocity Speed & -0.17 & 0.54 \\
MFES vs Cadence & -0.04 & 0.88 \\
MFES vs Endurance & -0.11 & 0.70 \\
MFES vs Level of Lesion & 0.44 & 0.08 \\
Level of Lesion vs Extent $x$ & -0.43 & 0.17 \\
Level of Lesion vs Extent $y$ & -0.34 & 0.22 \\
Level of Lesion vs Mean $x$ Speed & -0.44 & 0.10 \\
Level of Lesion vs Mean $y$ Speed & -0.34 & 0.22 \\
Level of Lesion vs Velocity Moment & -0.45 & 0.10 \\
\hline *Significant at $\leq 0.05$. & & \\
MFES = Modified Falls Efficacy Scale. & & \\
\hline \hline
\end{tabular}

ation in the functional outcome of rehabilitation for individuals with SCI. We measured the scientific relation between FOF and postural sway while considering lesion level and gait parameters.

FOF, or the self-efficacy or confidence in performing activities without falling, is multifactorial [8,22-23]. It can be influenced by patient characteristics, such as physical capabilities and psychological status and the physical environment. In the present study, the participants' lesion levels were T8 to L1 (AIS level A), making the group comparable in their physical abilities (the potential to ambulate with KAFOs and elbow crutches). The study environment was a stable platform, which gives a feeling of safety and gets the best possible results in the quiet stance postural sway measurements. The participants were in the final stages of their rehabilitation program, which involves the same training protocols, so the psychological inputs were more or less equal.

The postural sway measurements ( $x$-axis speed, $y$-axis speed, Extent $x$, and Extent $y$ ) showed a statistically significant $(p \leq 0.05)$ negative correlation with the MFES scores. Therefore, the participants who had higher scores (i.e., participants with more FOF) in the MFES had less range of movement (i.e., better stability) recorded in either directions. ADL performance imposes considerable challenges in the postural stability of individuals with paraplegia using KAFOs and elbow crutches. Use of the upper limbs are the main possibility of an individual with 
paraplegia to attain independence in his or her ADLs [24]. Upper-limb use in the standing position requires high levels of postural control. The decreased deviance of the COP should be an expected positive functional gain for an individual with paraplegia. In the present study, all participants showed good stability in their static measurements.

Even though the balance measurements showed stability, all participants were fearful while performing ADLs. This reveals the difference between perceptions and clinical measurements. Patients with SCI will physically and emotionally adjust to performing activities in a new way and this might contribute to improved selfefficacy perception. These adjustments are highly individualized to each patient and need careful assessment to promote maximum outcome of the rehabilitation program [25]. In the present study, participants underwent training in the ADL but still doubted their ability to replicate activities in their future life. The solution to overcoming decreased confidence can be the inclusion of home-based, individually tailored rehabilitation sessions.

The findings of this study are of high importance in the rehabilitation of individuals with paraplegia. The use of bilateral KAFOs and elbow crutches to ambulate has a tremendous energy cost [26]. Decreased self-efficacy in performing ADLs could contribute to nonuse of the KAFOs in the future. Patients who choose to use bilateral KAFOs as their preferred method of mobility must be provided with more confidence-building measures than patients who choose a wheelchair.

FOF and gait parameters also showed negative correlations but were not statistically significant. Further studies with instrumented gait analysis might explore the complete association between FOF and gait parameters. We found a statistically insignificant positive correlation between lesion level and force platform measurements. Though the results were not statistically significant, the positive correlation could be due to the differences in neurological levels of injury within the study group, i.e., participants with T8 and T9 lesion levels possibly had more instability than their counterparts with T12 and L1 lesion levels. Furthermore, in the present study, inclusion criteria controlled factors (associated medical complications; amount and nature of rehabilitation; and individual factors such as age, sex, and activity level) that might influence functional stability. Future studies should focus on establishing an acceptable level of FOF scores and developing the normative data of postural sway values in individuals with paraplegia.

\section{CONCLUSIONS}

The present study showed an association between FOF and the postural control of the participants with paraplegia. The FOF was negatively correlated with the postural sway measurements in quiet stance. Clinicians should consider FOF as an influential factor in postural control during rehabilitation of individuals with paraplegia.

\section{ACKNOWLEDGMENTS}

\section{Author Contributions:}

Study concept and design: L. T. John, B. Cherian.

Acquisition, analysis, and interpretation of data: L. T. John.

Drafting of manuscript: B. Cherian.

Critical revision of manuscript for important intellectual content:

B. Cherian.

Administrative, technical, or material support: A. Babu.

Study supervision: B. Cherian, A. Babu.

Financial Disclosures: The authors have declared that no competing interests exist.

Funding/Support: This material was unfunded at the time of manuscript preparation.

Additional Contributions: We are grateful to Drs. George Tharion and Ashish Macaden and the entire rehabilitation team for being sources of inspiration and support throughout this research. Mr. Cherian is now with Clinicenta, Oxford, United Kingdom. Institutional Review: The research review committee of the Physiotherapy Service, Department of Physical Medicine and Rehabilitation, Christian Medical College, reviewed and ethically approved this study.

Participant Follow-Up: The authors do not plan to inform participants of the publication of this study.

\section{REFERENCES}

1. Weber D. Orthotic management of spinal cord injury. In: Weber D, editor. Clinical aspects of lower extremity orthotics. Winnipeg (Canada): Canadian Association of Prosthetists and Orthotists; 1990.

2. Buchanan LE, Nawoczenski DA. Spinal cord injury: Concepts and management approaches. Baltimore (MD): Williams \& Wilkins; 1987.

3. Merritt JL, Yoshida MK. Knee-ankle-foot orthoses: Indications and practical applications of long leg braces. Phys Med Rehabil State Art Review. 2000;14:395-420.

4. Somers MF. Spinal cord injury: Functional rehabilitation. 2nd ed. Upper Saddle River (NJ): Prentice Hall; 2001.

5. Kannus P, Niemi S, Palvanen M, Parkkari J. Continuously increasing number and incidence of fall-induced, fractureassociated, spinal cord injuries in elderly persons. Arch 
Intern Med. 2000;160(14):2145-50. [PMID: 10904457] DOI:10.1001/archinte.160.14.2145

6. Krause JS. Factors associated with risk for subsequent injuries after traumatic spinal cord injury. Arch Phys Med Rehabil. 2004;85(9):1503-8. [PMID: 15375825] DOI:10.1016/j.apmr.2004.01.017

7. Brotherton SS, Krause JS, Nietert PJ. A pilot study of factors associated with falls in individuals with incomplete spinal cord injury. J Spinal Cord Med. 2007;30(3):243-50. [PMID: 17684890]

8. Brotherton SS, Krause JS, Nietert PJ. Falls in individuals with incomplete spinal cord injury. Spinal Cord. 2007; 45(1):37-40. [PMID: 16491105]

DOI:10.1038/sj.sc.3101909

9. Sharaf AY, Ibrahim HS. Physical and psychosocial correlates of fear of falling: Among older adults in assisted living facilities. J Gerontol Nurs. 2008;34(12):27-35.

[PMID: 19113001]

DOI:10.3928/00989134-20081201-07

10. Adkin AL, Frank JS, Jog MS. Fear of falling and postural control in Parkinson's disease. Mov Disord. 2003;18(5): 496-502. [PMID: 12722162]

DOI:10.1002/mds.10396

11. Andersson AG, Kamwendo K, Appelros P. Fear of falling in stroke patients: Relationship with previous falls and functional characteristics. Int J Rehabil Res. 2008;31(3):261-64. [PMID: 18708851] DOI:10.1097/MRR.0b013e3282fba390

12. Lin KH, Lu TW, Hsu PP, Yu SM, Liao WS. Postural responses during falling with rapid reach-and-grasp balance reaction in patients with motor complete paraplegia. Spinal Cord. 2008;46(3):204-9. [PMID: 17621310] DOI:10.1038/sj.sc.3102100

13. Era P, Saino P, Koskinen S, Haavisto P, Vaara M, Aromaa A. Postural balances in a random sample of 7,979 subjects aged 30 years and over. Gerontology. 2006;52(4):204-13. [PMID: 16849863] DOI:10.1159/000093652

14. Maynard FM Jr, Bracken MB, Creasey G, Ditunno JF Jr, Donovan WH, Ducker TB, Garber SL, Marino RJ, Stover SL, Tator CH, Waters RL, Wilberger JE, Young W. International Standards for Neurological and Functional Classification of Spinal Cord Injury. American Spinal Injury Association. Spinal Cord. 1997;35(5):266-74. [PMID: 9160449] DOI:10.1038/sj.sc.3100432

15. Jonsson M, Tollbäck A, Gonzales H, Borg J. Inter-rater reliability of the 1992 International Standards for Neurological and Functional Classification of Incomplete Spinal Cord Injury. Spinal Cord. 2000;38(11):675-79. [PMID: 11114774] DOI:10.1038/sj.sc.3101067

16. Dobkin BH, Apple D, Barbeau H, Basso M, Behrman A, Deforge D, Ditunno J, Dudley G, Elashoff R, Fugate L, Harkema S, Saulino M, Scott M. Methods for a randomized trial of weight-supported treadmill training versus conventional training for walking during inpatient rehabilitation after incomplete traumatic spinal cord injury. Neurorehabil Neural Repair. 2003;17(3):153-67. [PMID: 14503436] DOI:10.1177/0888439003255508

17. Hill KD, Schwarz JA, Kalogeropoulos AJ, Gibson SJ. Fear of falling revisited. Arch Phys Med Rehabil. 1996;77(10): 1025-29. [PMID: 8857881] DOI:10.1016/S0003-9993(96)90063-5

18. Parry SW, Steen N, Galloway SR, Kenny RA, Bond J. Falls and confidence related quality of life outcome measures in an older British cohort. Postgrad Med J. 2001;77(904): 103-8. [PMID: 11161077] DOI:10.1136/pmj.77.904.103

19. Behrman AL, Harkema SJ. Locomotor training after human spinal cord injury: A series of case studies. Phys Ther. 2000;80(7):688-700. [PMID: 10869131]

20. Kejonen P, Kauranen K. Reliability and validity of standing balance measurements with a motion analysis system. Physiotherapy. 2002;88(1):25-32. DOI:10.1016/S0031-9406(05)60526-3

21. SPSS. Statistical package for social sciences. 17.0 ed. Chicago (IL): SPSS; 2008.

22. Campbell AJ, Robertson MC. Implementation of multifactorial interventions for fall and fracture prevention. Age Ageing. 2006;35(S2):ii60-ii64. [PMID: 16926208] DOI:10.1093/ageing/afl089

23. Scheffer AC, Schuurmans MJ, Van Dijk N, Van der Hooft T, De Rooij SE. Fear of falling: Measurement strategy, prevalence, risk factors and consequences among older persons. Age Ageing. 2008;37(1):19-24. [PMID: 18194967] DOI:10.1093/ageing/afm169

24. Umphred DA. Neurological rehabilitation. 3rd ed. St. Louis (MO): Mosby; 1995.

25. Craig A, Hancock K, Dickson H. Improving the long-term adjustment of spinal cord injured persons. Spinal Cord. 1999; 37(5):345-50. [PMID: 10369171$]$ DOI:10.1038/sj.sc.3100829

26. Waters RL, Mulroy S. Energy expenditure in normal and pathologic gait. Gait Posture. 1999;9(3):207-31.

[PMID: 10575082] DOI:10.1016/S0966-6362(99)00009-0

Submitted for publication September 17, 2009. Accepted in revised form March 15, 2010.

This article and any supplementary material should be cited as follows:

John LT, Cherian B, Babu A. Postural control and fear of falling in persons with low-level paraplegia. J Rehabil Res Dev. 2010;47(5):497-502.

DOI:10.1682/JRRD.2009.09.0150 